\title{
Adhesive interactions between gelatinised starch granules
}

\author{
Salah Mohamed Hasan ${ }^{1}$, Agoub Abdella Agoub ${ }^{1}$, Ramadan Elsalhin Abdolgader ${ }^{1}$, \\ Eileen O'Neill' ${ }^{2}$, Edwin Morris ${ }^{2}$ \\ ${ }^{1}$ Department of Food Science and Technology, Omar al Mukhtar University, El-Beida, Libya \\ ${ }^{2}$ Department of Food and Nutritional Sciences, Cork University, Cork, Ireland
}

Email address:

rabdolgader@yahoo.ca (R. E. Abdolgader)

To cite this article:

Salah Mohamed Hasan, Agoub Abdella Agoub, Ramadan Elsalhin Abdulgader, Eileen O'Neill, Edwin Morris. Adhesive Interactions between Gelatinised Starch Granules. International Journal of Nutrition and Food Sciences. Vol. 2, No. 4, 2013, pp. $207-212$.

doi: 10.11648/j.ijnfs.20130204.18

\begin{abstract}
Different starches were extracted from wheat flour and maize flour. Thermal transitions can be monitored directly by the technique of differential scanning calorimetry (DSC). Two peaks were observed the first peak refer to the gelatinization temperatures where occurred at $\sim 53-54^{\circ} \mathrm{C}$ and the second peak was attributed to the dissociation of amylose-lipid complex. In addition the rheological properties of starches from wheat and maize flours were characterized by using low-amplitude oscillation. The results showed that Starch samples formed weak-gel networks by association between swollen granules. Blue dextrin method was also used to determine the swelling volume of heated and unheated wheat starch. The results indicated that gel-like character concentrations below close-packing.
\end{abstract}

Keywords: Wheat Flour, Preheated Wheat Flour, DSC, Gelatinization, Gel

\section{Introduction}

The normal interpretation of the rheology of starch in high-moisture systems [1-3] can be summarised in the following:- with heating in excess water, the ordered (double helix) structure of amylopectin dissociates and the granules swell (gelatinisation) [1], thickening occurs by physical contacts between the gelatinised granules [2], disordered amylose leaches out, at very high temperatures and shear rates, further release of polysaccharides can occur by disintegration of swollen granules [3], with cooling and storage, amylose may form a network crosslinked by aggregated double helices. At longer times, amylopectin may also re-order into double helices; these ordering processes are known collectively as retrogradation [3].

The central conclusion from the work reported here is that when starch is gelatinised under quiescent conditions (i.e. without stirring or other mechanical agitation), physical contacts resulting from space-occupancy by swollen granules are augmented, or superseded, by adhesive interactions (i.e. by granules associating with one another).

The results presented came from two otherwise unrelated studies. The first [4] was an investigation of the effect of pre-heating wheat flour on its subsequent rheology when heated and cooled in excess water, and included rheological characterisation of starch extracted from heated flour and from an unheated control. The second was an investigation [5] of the co-gels formed by heating mixtures of whey protein isolate with waxy maize starch.

\section{Materials and Methods}

The waxy maize starch used was a hydroxypropylated preparation crosslinked by phosphorus oxychloride (C*Polartex 06716 from Cerestar). White flour from soft wheat was obtained from Odlum Group Ltd., Dublin, and contained $13 \%$ moisture, $74 \%$ starch, $9.1 \%$ protein, $2.8 \%$ fat and $0.26 \%$ ash. Heating $\left(30 \mathrm{~min}\right.$ at $125^{\circ} \mathrm{C}$ ) was carried out in sealed pouches of aluminium foil. Starch from heated flour and unheated control was obtained [4] as the residue remaining after sequential extraction of protein [6-7]. The residue was rinsed $(3 \times)$ with water, compacted by centrifugation, and separated manually into prime starch and tailings starch [7]. Only the prime starch fraction was used.

Differential scanning calorimetry (DSC) measurements were made at a heating rate of $0.5^{\circ} \mathrm{C} / \mathrm{min}$ on a Setaram DSC III microcalorimeter, using $10.0 \mathrm{wt} \%$ aqueous slurries of starch, with water as thermal reference. Sample and 
reference pans (typical loading $\sim 850 \mathrm{mg}$ ) were balanced to within $\pm 0.5 \mathrm{mg}$. Rheological measurements were made on a CarriMed CSL-100 rheometer, using parallel plate geometry of diameter $40 \mathrm{~mm}$ and gap $0.5 \mathrm{~mm}$. Starch slurries were loaded at $40^{\circ} \mathrm{C}$ and coated around their periphery with light silicone oil, to minimize loss of water by evaporation.

Determination of swelling volume: Starch $(\sim 3.5 \mathrm{wt} \%)$ from heated and unheated wheat flour was gelatinised by heating for $15 \mathrm{~min}$ at $90^{\circ} \mathrm{C}$ and cooled to ambient temperature. Swollen granules were then sediment by centrifugation $(15 \mathrm{~min}$ at $1500 \times \mathrm{g})$, and swelling volume $(\mathrm{Q})$ was determined from the mass of sediment relative to the total mass of the sample. The values obtained were virtually identical $(\mathrm{Q}=9.62 \mathrm{ml} / \mathrm{g}$ for starch from heated wheat flour and $\mathrm{Q}=9.56 \mathrm{ml} / \mathrm{g}$ for the unheated control). Complete space-occupancy ( $\mathrm{cQ}=1.0$ ) by fully-swollen granules would therefore occur at a concentration (c) of $~ 10.4-10.5$ wt $\%$ for both, and the onset of close-packing ( $65 \%$ space-occupancy; $\mathrm{cQ}=0.65$ ) at $\sim 6.8 \mathrm{wt} \%$.

The swelling volume of the phosphate-cross linked waxy maize starch was determined [5] by the polymer exclusion method [8], using blue dextran (from Sigma). The principle of the method is that polymer molecules cannot penetrate starch granules. Swelling of the granules on gelatinisation in a polymer solution increases the concentration of polymer in the surrounding liquid, and the volume occupied by the swollen granules can be determined from this increase (which, for blue dextran, can be quantified by measuring the optical density of the supernatant after sedimentation of the swollen granules by centrifugation). The swelling volume obtained in this way for cross linked waxy maize starch was $\mathrm{Q}=11.9 \mathrm{ml} / \mathrm{g}$, which agreed well with the value derived by measurement of the mass of sediment granules after centrifugation. An attempt to determine the swelling volume of starch from heated wheat flour by exclusion of blue dextran was unsuccessful, but informative.

\section{Results and Discussion}

\subsection{Differential Scanning Calorimetry (DSC)}

As shown in Figure 1, the DSC traces obtained for starch from heated and unheated wheat flour were closely similar, indicating that pre-heating the flour has little effect on the ordered structure of the starch component. Both traces show an intense gelatinisation endothermic centered at $\sim 53-54^{\circ} \mathrm{C}$, followed by a much smaller endothermic at higher temperature $\left(\sim 95^{\circ} \mathrm{C}\right)$, which can be attributed[9] to dissociation of amylose-lipid complex. The onset of gelatinisation occurs (Figure 1) at $\sim 40^{\circ} \mathrm{C}$, which was used as the loading temperature in the rheological studies reported below, to minimize sedimentation of un-swollen granules.

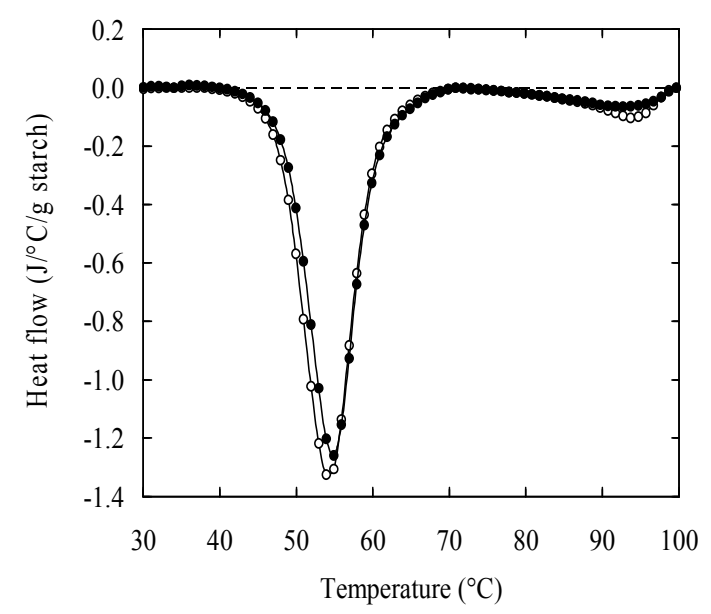

Figure 1.DSC heating curves $\left(0.5^{\circ} \mathrm{C} / \mathrm{min}\right.$; baselines subtracted) for $10.0 \mathrm{wt} \%$ starch from heated $(\bullet)$ and unheated $(O)$ wheat flour

\subsection{Changes in Moduli on Heating and Cooling}

Figure 2 shows the changes in $\mathrm{G}^{\prime}$ (Figure 2a) and $\mathrm{G}^{\prime \prime}$ (Figure 2b), recorded at $10 \mathrm{rad} \mathrm{s}^{-1}$ and $1 \%$ strain, during heating $\left(40-90^{\circ} \mathrm{C}\right)$ and cooling $\left(90-5^{\circ} \mathrm{C}\right)$ at $1{ }^{\circ} \mathrm{C} / \mathrm{min}$ for starch from heated wheat flour, and from the unheated control. The starch concentration used was $7.4 \mathrm{wt} \%$, chosen to match the concentration in $10.0 \mathrm{wt} \%$ flour (starch content $74 \%)$.

The control starch shows a sharp increase in both moduli in the early stages of heating, as would be expected from gelatinisation and swelling of the granules, followed by a reduction at temperatures approaching $90^{\circ} \mathrm{C}$, which can be attributed[2] to some loss of granule structure. The traces recorded on subsequent cooling to $5^{\circ} \mathrm{C}$ are comparatively featureless, showing only small, monotonic increases in $\mathrm{G}^{\prime}$ and $\mathrm{G}^{\prime \prime}$. The changes in moduli observed for starch from heated wheat flour are similar in form, but the absolute values of both moduli are consistently higher throughout heating and cooling.

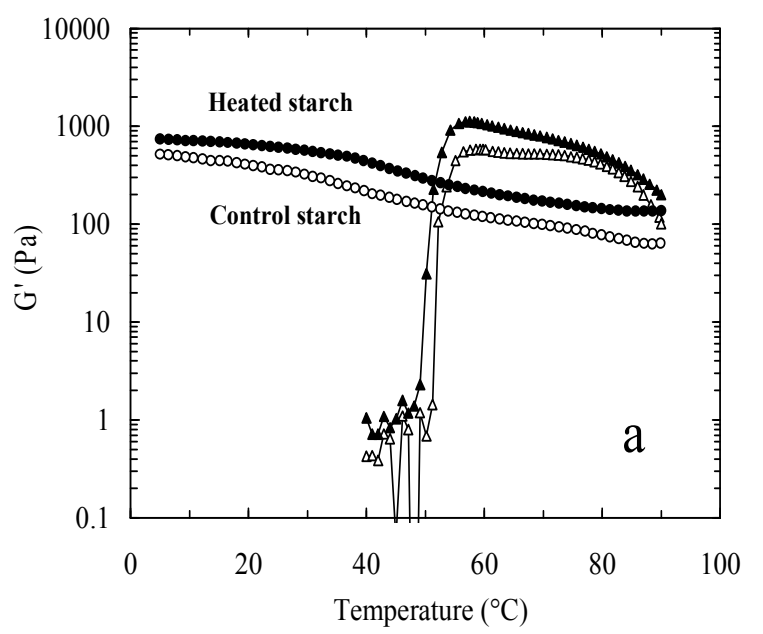




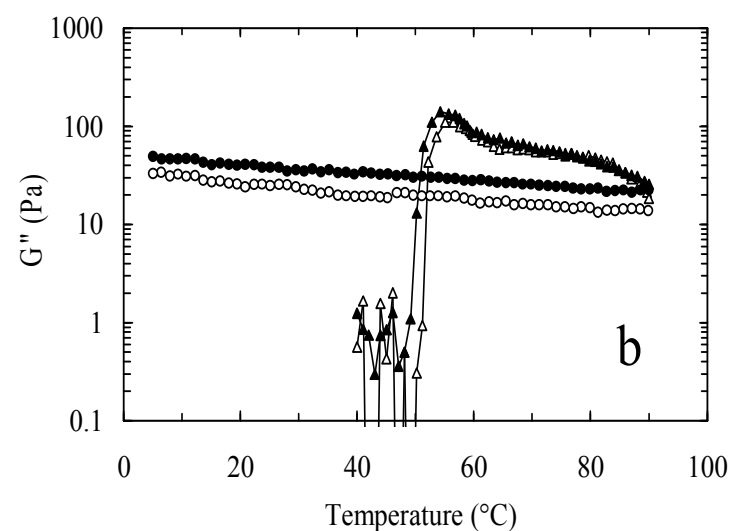

Figure 2.Changes in (a) $G^{\prime}$ and (b) $G^{\prime \prime}$ (10 rad s $\mathrm{s}^{-1} ; 1 \%$ strain) during heating (triangles) and cooling (circles) at $1.0^{\circ} \mathrm{C} / \mathrm{min}$ for $7.4 \mathrm{wt} \%$ starch from heated (filled symbols) and unheated (open symbols) wheat flour

\subsection{Rheology after Gelatinisation under Ouiescent Conditions}

The mechanical spectra recorded for the same samples after completion of heating and cooling (Figure 2) are shown in Figure 3. Both spectra have obvious gel-like character [10] $\left(G^{\prime}>G^{\prime \prime}\right.$; little variation of $G^{\prime}$ with frequency, ; steep, linear reduction in $\log *$ on increasing log , with a slope close to -1), but the values of $G^{\prime}, G^{\prime \prime}$ and * for starch from the heated wheat flour are about twice those of the unheated control. This enhancement in rheology cannot be attributed to greater space-occupancy since, as reported in Section 3, both samples have virtually the same swelling volume $(\sim 9.6$ $\mathrm{ml} / \mathrm{g}$ ).

The moduli recorded after heating and cooling under quiescent conditions (low-amplitude oscillation at $10 \mathrm{rad} \mathrm{s}-1$ and $1 \%$ strain) over a range of values of starch concentration

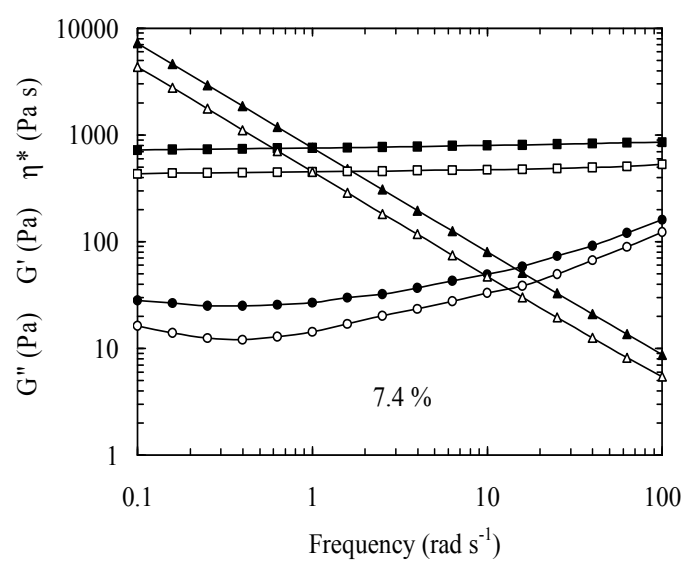

Figure 3. Mechanical spectra $\left(5^{\circ} \mathrm{C} ; 1 \%\right.$ strain) showing the frequency-dependence of $G^{\prime}$ (squares), $G^{\prime \prime}$ (circles) and $\eta^{*}$ (triangles) for $7.4 \mathrm{wt} \%$ starch from heated (filled symbols) and unheated (open symbols) wheat flour after gelatinisation under low-amplitude oscillation

(c $=1.0$ to $10.0 \mathrm{wt} \%$ ) are also inconsistent with simple physical contacts between swollen granules. As shown in Figure 4, the plot of $\log G^{\prime}$ versus $\log$ c for starch from unheated wheat flour is broadly similar to those obtained for gelling biopolymers [11], with a progressive increase in slope as concentration is decreased towards the minimum critical gelling concentration $\left(c_{0}\right)$ and a limiting slope of $\sim 2$ $\left(c^{2}\right.$-dependence of $\left.\mathrm{G}^{\prime}\right)$ at $\mathrm{c}>>\mathrm{c}_{\mathrm{o}}$. In particular, there is no evidence of any sudden increase in moduli, or other discontinuity in the concentration-dependence of $\mathrm{G}^{\prime}$ or $\mathrm{G}^{\prime \prime}$, as the degree of space-occupancy approaches and exceeds the onset of close-packing (at $\mathrm{cQ} \approx 0.65$ ). Similar concentration-dependence of moduli was observed for starch from heated wheat flour[4] and for crosslinked waxy maize starch, [5] with again no discontinuity at the onset of close-packing.

As shown in Figure 5a, the mechanical spectrum obtained for the control sample of wheat starch at a concentration of $2.5 \mathrm{wt} \%$, where the swollen granules occupy less than a quarter of the total volume $(\mathrm{cQ}=0.24)$, is predominantly gel-like:

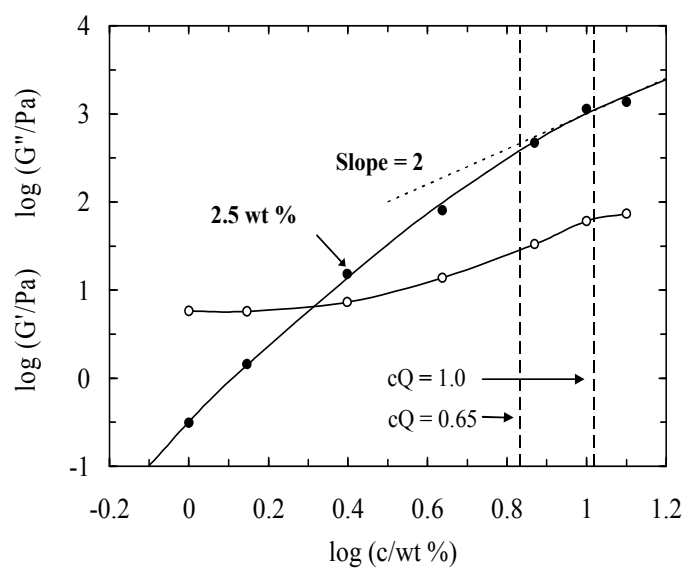

Figure 4. Concentration-dependence of $G^{\prime}(\bullet)$ and $G^{\prime \prime}(O)$, measured (10 rad $\mathrm{s}^{-1} ; 1 \%$ strain) at $5^{\circ} \mathrm{C}$ after heating and cooling under low-amplitude oscillation, for starch from unheated wheat flour

$\mathrm{G}^{\prime}$ is virtually independent of frequency across the range studied $\left(0.1\right.$ to $\left.100 \mathrm{rad} \mathrm{s}^{-1}\right)$ and at low frequencies it exceeds $\mathrm{G}^{\prime \prime}$ by more than an order of magnitude. The upturn in $\mathrm{G}^{\prime \prime}$ at higher frequencies can be readily explained by a significant "sol fraction" of material that does not form part of the gel network.

Formation of a continuous network at concentrations far below those at which the swollen granules are forced into contact with one another cannot be explained by gelation of the amylose component of the wheat starch since, as shown in Figure 5b, a similar gel-like spectrum was obtained [5] at the same low degree of space-occupancy $(\mathrm{cQ}=0.24)$ for cross linked waxy maize starch, which, like any waxy starch, is of course essentially devoid of amylose. Because of it's somewhat higher swelling volume $(11.9 \mathrm{ml} / \mathrm{g}$ in comparison with $9.56 \mathrm{ml} / \mathrm{g}$ for the wheat starch), however, the concentration of the waxy maize starch at $\mathrm{cQ}=0.24$ is lower ( $2.0 \mathrm{wt} \%$ in comparison with $2.5 \mathrm{wt} \%$ ), and the moduli are also lower (Figure 5), as would be expected for conventional gelling biopolymers. 

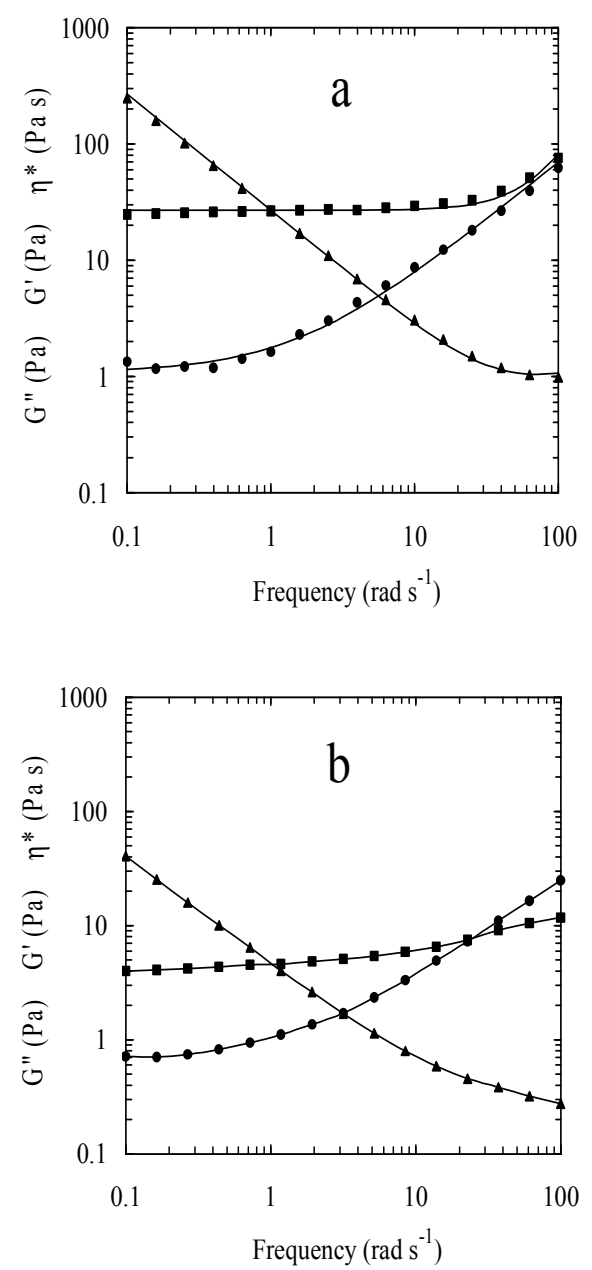

Figure 5. Mechanical spectra showing the frequency-dependence of $G^{\prime}(\boldsymbol{\square})$ $G^{\prime \prime}(\boldsymbol{\bullet})$ and $\eta^{*}(\boldsymbol{\Lambda})$ after gelatinisation under low-amplitude oscillation at the same degree of space-occupancy $(c Q=0.24)$ for (a) starch from unheated wheat flour ( $c=0.25 \mathrm{wt} \% ; Q=9.56 \mathrm{ml} / \mathrm{g}$ ) and (b) crosslinked waxy maize starch $(c=0.20 \mathrm{wt} \% ; Q=11.9 \mathrm{ml} / \mathrm{g})$

The obvious interpretation of all the rheological evidence presented so far is that starch, when gelatinised under quiescent conditions, forms continuous networks by associative interactions (i.e. by the swollen granules adhering to one another).

The enhanced rheology (Figures 2 and 3) of starch from heated wheat flour indicates that pre-heating the flour increases the adhesiveness of the gelatinised granules, which is consistent with an unexpected change in their interaction with blue dextran, reported below.

\subsection{Interaction with Blue Dextran}

When starch from unheated wheat flour was gelatinised in a solution of blue dextran, swelling of the granules caused the expected increase in concentration of polymer in the surrounding liquid, and the swelling volume calculated from this increase was $\mathrm{cQ}=9.56 \mathrm{ml} / \mathrm{g}$ derived by sedimentation of the swollen granules. When the same procedure was applied to starch from heated wheat flour, however, the concentration of blue dextran in the solution phase decreased, rather than increasing and the gelatinised granules had a deep blue colour which persisted after repeated rinsing with water.

This behavior is unlikely to have arisen from penetration of blue dextran into the granules, particularly since DSC (Figure 1) showed no evidence of any significant change in their internal structure prior to gelatinisation. The most likely interpretation is that the exterior of the granules is modified during pre-heating of the flour (possibly by changes in surface protein), with the modified surface then being capable of binding to the dye chromophores of blue dextran, and of causing stronger adhesion between gelatinised granules (with consequent enhancement of network structure).

\subsection{Effect of Shearing during Gelatinsation}

In systems where interactions are limited to physical contacts (e.g. solutions of entangled polymer coils) the frequency-dependence of $\eta^{*}$ and shear-rate dependence of viscosity $(\eta)$ superimpose closely[10] when comparison is made at equivalent numerical values of frequency $\left(\omega / \mathrm{rad} \mathrm{s}^{-1}\right)$ and shear rate $\left(\dot{\gamma} / \mathrm{s}^{-1}\right)$. However, departures from this generality (which is known as the "Cox-Merz rule") [12] occur for weakly-cross linked networks that remain interacted under low-amplitude oscillation but are broken down by shear[10], giving $\eta^{*}>\eta$.

In the studies reported here, comparisons were made using a frequency of $10 \mathrm{rad} \mathrm{s}^{-1}$ and a shear rate of $10 \mathrm{~s}^{-1}$. These values were chosen as a compromise between the conflicting considerations of having a shear rate high enough to give reliable measurements and approximate to normal processing conditions in industry and a frequency low enough to prevent the elastic response of any crosslinked network structure from being obscured by simple physical interactions, which make a progressively greater contribution to overall resistance as the frequency of oscillation is increased [10].

The results obtained are illustrated in Figure 6 for $7.4 \mathrm{wt} \%$ starch from unheated wheat flour. The increase in $\eta^{*}$ on gelatinisation is substantially greater than the corresponding increase in $\eta$, and $\eta^{*}$ then remains above $\eta$ throughout further heating and subsequent cooling, giving a value of $\eta^{*}$ about 5 times higher than that of $\eta$ on completion of cooling to $5^{\circ} \mathrm{C}$. Similar violation of the Cox-Merz rule was observed[12] for starch from heated wheat flour, and, as discussed above, strongly indicates associative interactions that can survive the low-amplitude used in measurement of $\eta$ * but are disrupted by rotational measurements of $\eta$. Further Cox-Merz comparisons were made for starch from both heated and unheated wheat flour on completion of cooling to $5^{\circ} \mathrm{C}$ after gelatinisation under unperturbed conditions and under shear at starch concentrations ranging from 1.0 to 10.0 wt $\%$. 


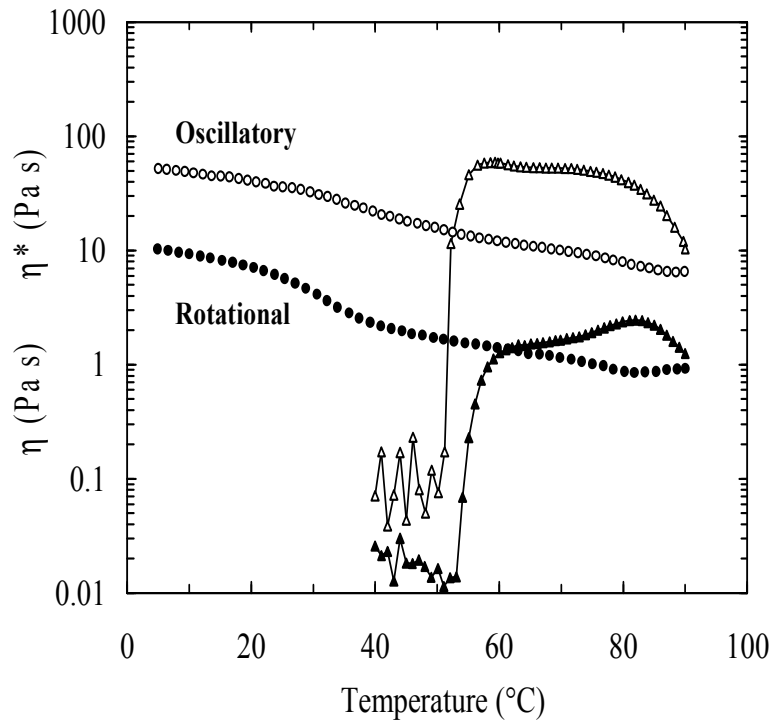

Figure 6. Comparison of $\eta^{*}$ from oscillatory measurements at $10 \mathrm{rad} \mathrm{s}^{-1}$ (open symbols) and $\eta$ from rotational measurements at $10 \mathrm{~s}^{-1}$ (filled symbols) during heating (triangles) and cooling (circles) for $7.4 \mathrm{wt} \%$ starch from unheated wheat flour.

Figure 7 shows comparisons of the final values of $\eta\left(10 \mathrm{~s}^{-1}\right)$ for the sheared samples with the corresponding values of $\eta^{*}$ $\left(10 \mathrm{rad} \mathrm{s}^{-1}\right)$ for the same sheared preparations (obtained by oscillatory measurements immediately after completion of cooling) and for equivalent samples prepared by heating and cooling under oscillation (as in Figure 2). The values of $\eta^{*}$ for the samples gelatinised under oscillation are consistently higher than the corresponding values of $\eta$ for the sheared samples, again indicating associations that can survive low-amplitude oscillation but are disrupted by shear. The sheared samples, by contrast, show reasonable Cox-Merz superposition $\left(\eta^{*} \approx \eta\right)$, indicating that shearing during gelatinisation prevents association, leaving only physical contacts between the gelatinised granules.

For both sheared and unsheared preparations, low-amplitude oscillatory measurements of $\eta^{*}\left(10 \mathrm{rad} \mathrm{s}^{-1} ; 1 \%\right.$ strain) were made over a period of 2 hours at $5^{\circ} \mathrm{C}$ after completion of cooling. No changes in $\eta^{*}$ were observed, ${ }^{4}$ demonstrating (i) that no further associations are formed by the samples gelatinised under unperturbed conditions and (ii) that the samples gelatinised under shear show no recovery from the disruption caused by shearing.

\section{Conclusions}

The main conclusions from the studies reported above can be summarized as follows.

- When starch is gelatinised under quiescent conditions (such as low-amplitude oscillation) the swollen granules adhere to one another, and form gel networks at concentrations well below the onset of close-packing (as illustrated in Figure 5 for both wheat starch and crosslinked waxy maize starch).

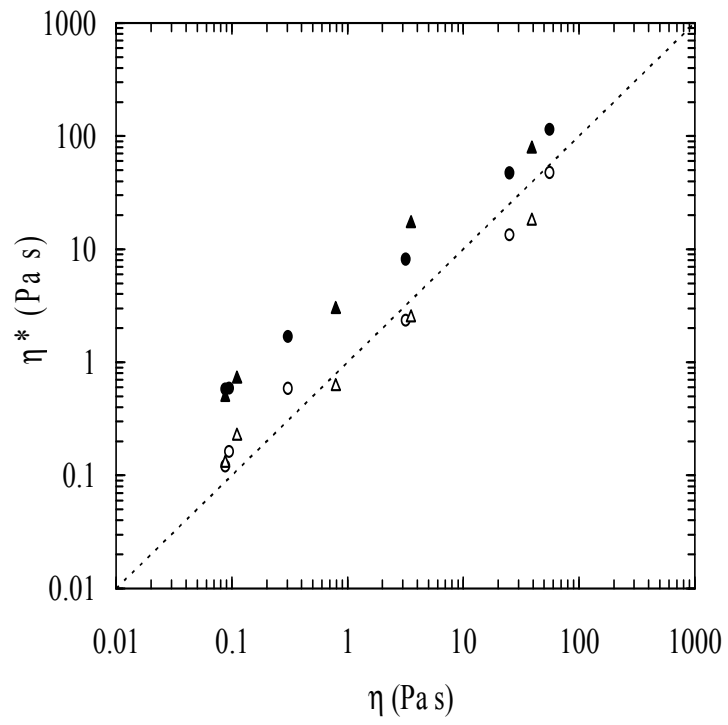

Figure 7. Comparison of oscillatory measurements of $\eta^{*}\left(10 \mathrm{rad} \mathrm{s}^{-1} ; 5^{\circ} \mathrm{C}\right)$ and rotational measurements of $\eta\left(10 \mathrm{~s}^{-1}\right)$ for sheared (open symbols) and un-sheared (filled symbols) preparations (1.0 - $10.0 \mathrm{wt} \%)$ of starch from heated (triangles) and unheated (circles) wheat flour. The dotted line corresponds to perfect agreement between $\eta$ and $\eta^{*}$ (Cox-Merz superposition)

- $\quad$ Pre-heating wheat flour increases the adhesiveness of the starch granules, giving higher moduli than for control starch from unheated flour, although the swelling volume remains virtually unchanged.

- Enhanced rheology indicates modification of the granule surface, which also leads to binding of blue dextran.

- $\quad$ Shearing (e.g. during rotational measurements of viscosity) prevents association of swollen granules.

- Disruption by shear is irreversible (sheared preparations showed no increase in $\eta^{*}$ on holding for $2 \mathrm{~h}$ at $5^{\circ} \mathrm{C}$ ).

- Evaluation of flours and starches by conventional measurements under shear

(e.g. Amylograph) is therefore appropriate for products such as soups and sauces which are stirred during processing (preventing association of swollen granules).

- $\quad$ The same procedures, however, may be misleading for baked products, where gelatinisation of starch occurs under quiescent conditions, allowing associations between gelatinised granules to form in the product, but not during rotational testing.

\section{Acknowledgements}

We thank Professor J.D. Schofield for helpful discussions. The results reported for crosslinked waxy maize starch emanated from research conducted with the financial support of Science Foundation Ireland. 


\section{References}

[1] Cooke, D. and Gidley, M. J. (1992): Loss of crystallization and molecular order during starch gelatinisation: origin of the enthalpic transition, Carbohydr. Res. 227: 103- 112. doi :10.1016/0008-6215(92)85063-6

[2] Evans, I. D. and Lips, A. (1992): Viscoelasticity of gelatinized starch dispersions, J. Text. Stud. 23: 69-86. doi:10.1111/j.1745-4603.1992.tb00512.x

[3] Keetels, C. J. A. M. van Vliet, T. and Walstra, P. (1996): Gelation and retrogradation of concentrated starch systems: 2 . Retrogradation, Food Hydrocolloids. 10: 355- 362. doi:10.1016/S0268-005X(96)80012-9

[4] Hasan, S. (2006): Heat Treatment of Wheat Flour, PhD Thesis, University College Cork, Ireland.

[5] Chiotelli, E. and Meste, M. L. (2002): Effect of small and large wheat starch granules on thermomechanical behavior of starch, Cereal Chem. 79: 286-293

[6] Johnson, A. C. and Hoseney, R. C. (1979): Chlorine treatment of cake flours. III. Fractionation and reconstitution techniques for $\mathrm{Cl}_{2}$ - treated and untreated flours. Cereal Chem. 57: 443-445.

[7] Kusanose, C. Noguchi, S. Yamagishi, T. and Seguchi, M. (2002): Binding of prime starch to tailings fraction by proteins in stored wheat flour. Food Hydrocolloids. 16: 73-77. doi:10.1016/S0268-005X(01)00032-7

[8] Nayouf, M. Loisel, C. and Doublier, J.L. (2003): Effect of thermomechanical treatment on the rheological properties of crosslinked waxy corn starch, J. Food Eng. 59: 209-219. doi:10.1016/S0260-8774(02)00460-0

[9] Donovan, J. W. Lorenz, K. and Kulp, K. (1983): Differential scanning calorimetry of heat-moisture treated wheat and potato starches. Cereal Chem. 60: 381387.

[10] Ross-Murphy, S.B. (1984): Rheological methods. In: Biophysical Methods in Food Research (ed. H> W. S. Chan). Critical Reports on Applied Chemistry. SCI, London , p. 195290.

[11] Clark, A.H. (1985): The application of network theory to food systems. In: Food Structure and Behavior (eds J. M. V. Blanshard and P. Lillford). Academic Press, London, pp. 13-34.

[12] Cox, W. P. and Merz, E. H. (1958): Correlation of dynamic and steady flow viscosities. J. Polym. Sci. 28: 619- 622. doi:10.1002/pol.1958.1202811812 